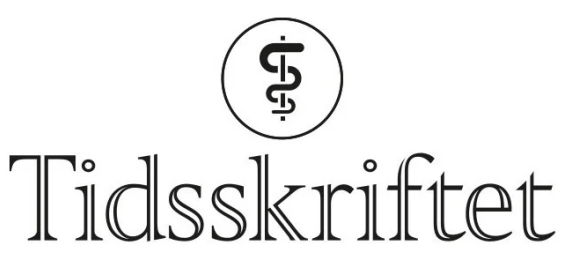

DEN NORSKE LEGEFORENING

\title{
Cerebrale arterielle karspasmer
}

\author{
MEDISINEN I BILDER
}

\section{MARTE HELENE BJØRK}

Marte Helene Bjørk (f. 1980) er ph.d. i nevrovitenskap og er lege i spesialisering ved Nevrologisk avdeling.

Oppgitte interessekonflikter: Hun fikk Pfizer-prisen 2010 for beste norske foredrag i utlandet. Email: mebk@helse-bergen.no

Nevrologisk avdeling

Haukeland universitetssykehus

\section{LARS THOMASSEN}

Lars Thomassen (f. 1947) er spesialist i nevrologi, professor ved Universitetet i Bergen og leder for Senter for nevrovaskulære sykdommer, Haukeland universitetssykehus.

Ingen oppgitte interessekonflikter.

Nevrologisk avdeling

Haukeland universitetssykehus

\section{ULRIKE WAJE-ANDREASSEN}

Ulrike Waje-Andreassen (f. 1962) er spesialist i nevrologi og overlege ved Nevrologisk avdeling. Ingen oppgitte interessekonflikter.

Nevrologisk avdeling

Haukeland universitetssykehus 

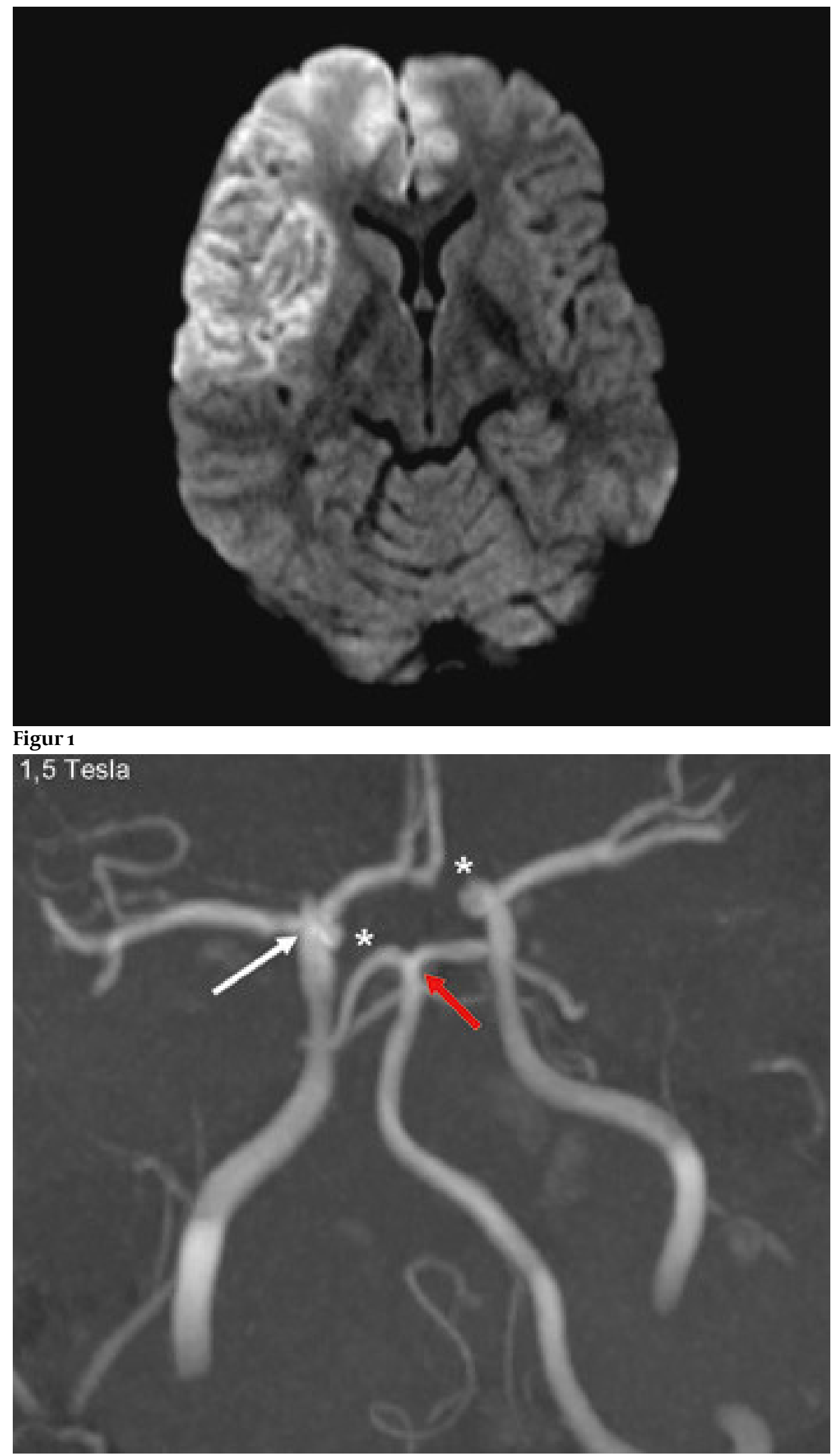

Figur 2 


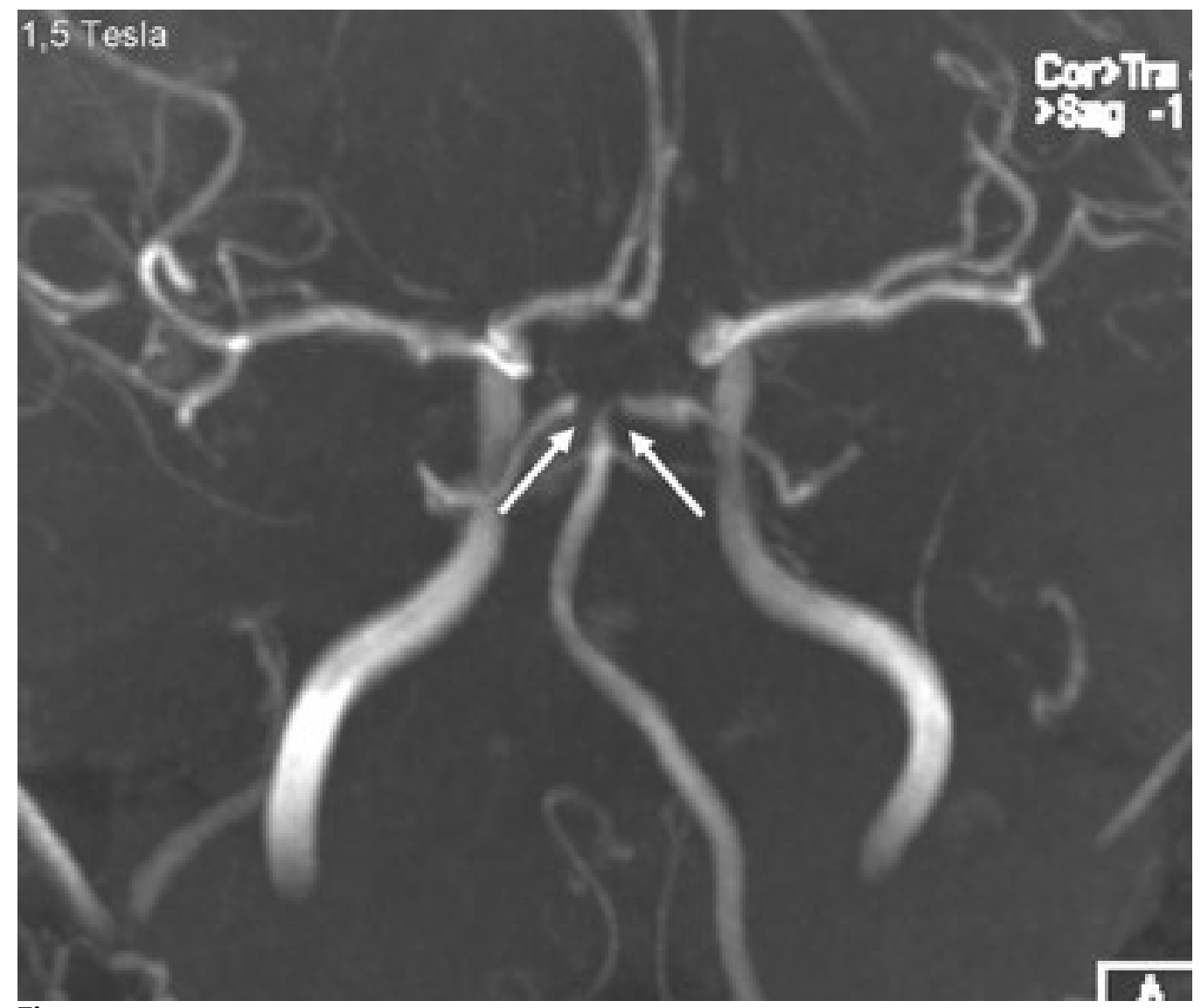

Figur 3

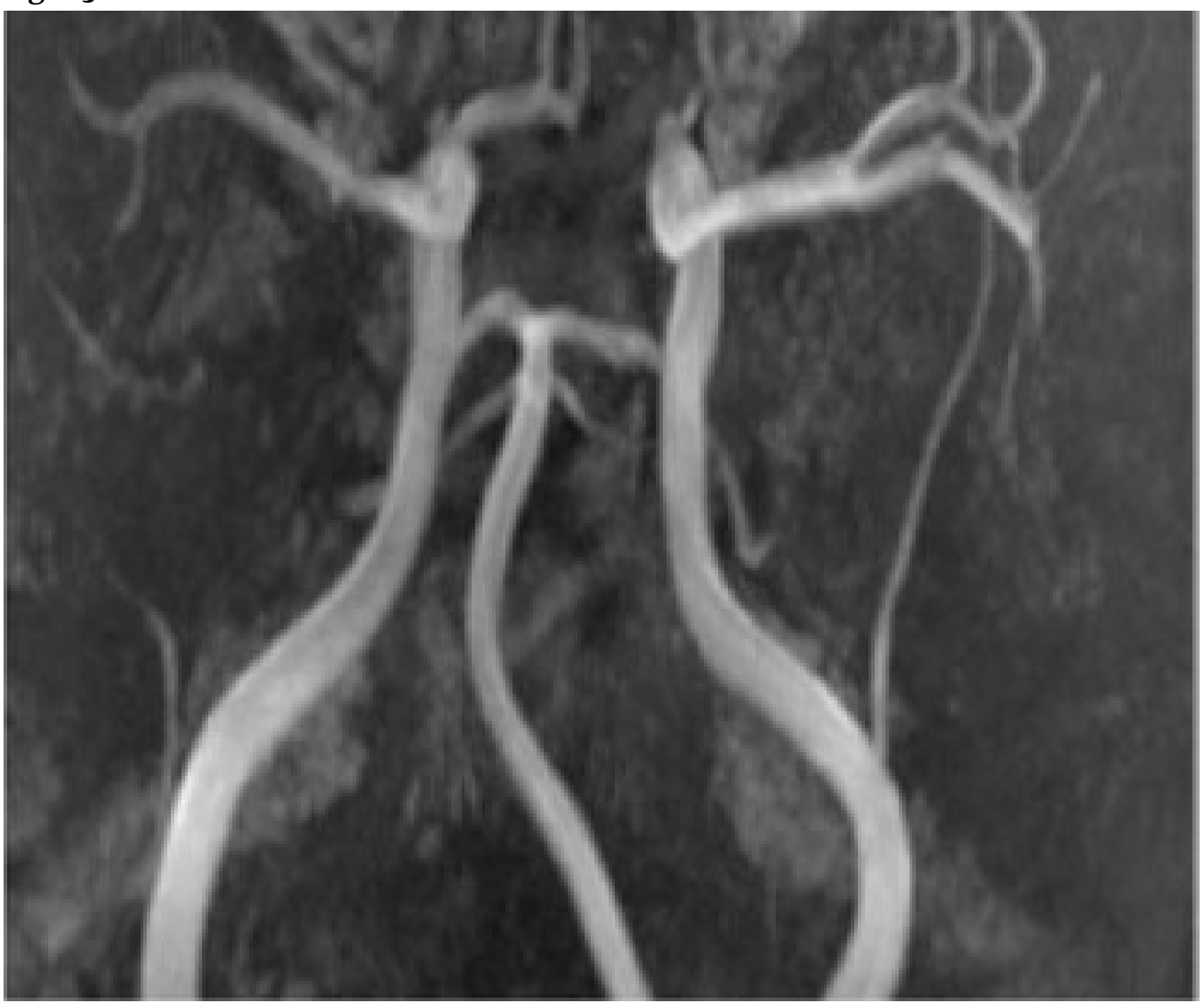

Figur 4

En person i 2o-årene med kjent migrene med aura fikk infarkter i høyre arteria cerebri media og begge anteriorgebet (figur 1 viser en magnettomografidiffusjonsvektet serie). Cerebral computer- og magnettomografi med blodstrømsangiografi (MRA) etter innleggelse viste upåfallende strømning uten tegn til disseksjon eller vaskulitt. Hemikraniektomi ble nødvendig etter utvikling av malignt hjerneødem. MR-angiografi i 
narkose dagen etter operasjonen viste åpne arterier (figur 2 viser en åpen carotistopp (hvit pil), normal basilaristopp (rød pil) samt en ikke-lukket Willis' sirkel, som er en anatomisk normalvariant (stjerner)). Testing på sentralstimulerende substanser, antikardiolipin, antinukleære antistoffer, nevronantistoffer og tumormarkører ga negative funn. Transøsofageal ekkokardiografi viste et minimalt patent foramen ovale, lite sannsynlig relatert til hendelsen, ifølge kardiolog. Pasienten utviklet alvorlig hjernestammeaffeksjon og MR-angiografi viste forsnevring i arteria basilaris posterior-forgreningen (pilene i figur 3). Arterielle karspasmer ble retrospektivt mistenkt. Den første mistenkte karspasmen i høyre media-/anteriorforgreningen forble udokumentert. Den andre i basilaris-/posteriorforgreningen ble dokumentert postoperativt (pilene i figur 3). Bildene av flere nytilkomne infarkter i bakre kretsløp vises ikke. Tre uker etter hemikraniektomi var ny angiografi normalisert (figur 4).

Pasienten brukte en boks løssnus med $400 \mathrm{mg}$ nikotin daglig. Korrigert for at $30 \% \mathrm{blir}$ absorbert, tilsvarer denne mengden nikotininnholdet i 173 sterke sigaretter. I kombinasjon med tobakk mer enn nidobler migrene med aura risikoen for hjerneslag. Karspasmer er en mistenkt årsaksfaktor. Nikotin er en kjent karkonstriktor, med provokasjon av karspasmer både under bruk og ved nikotinabstinens. Vi anser derfor høyt snusforbruk i kombinasjon med bakenforliggende migrene med aura som sannsynlig årsak til mistenkte cerebrale arterielle karspasmer i media-/anterior-forgreningen og basilaris-/posteriorforgreningen.

Pasienten har gitt samtykke til at artikkelen blir publisert.

Publisert: 23. august 2011. Tidsskr Nor Legeforen. DOI:10.4045/tidsskr.10.1427

Mottatt 21.12. 2010, første revisjon innsendt 3.4. 2011, godkjent 5.5. 2011. Medisinsk redaktør Michael Bretthauer.

(C) Tidsskrift for Den norske legeforening 2023. Lastet ned fra tidsskriftet.no 26. april 2023. 